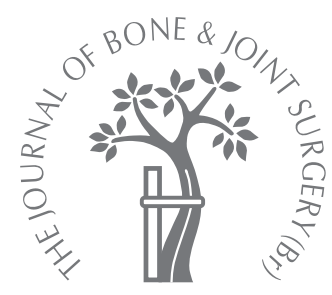

- ANNOTATION

\title{
A contemporary snapshot of the use of hydroxyapatite coating in orthopaedic surgery
}

\section{J. A. N. Shepperd, H. Apthorp}

From Conquest Hospital, East Sussex, England
J. A. N. Shepperd, FRCS, Consultant Orthopaedic Surgeon

H. Apthorp, Consultant Trauma and Orthopaedic Surgeon

Conquest Hospital, The Ridge, St Leonard's on Sea, East Sussex TN37 7RD, UK.

Correspondence should be sent to Mr J. A. N. Shepperd; e-mail:

rona.drennan@esht.nhs.uk

(C)2005 British Editorial Society of Bone and Joint Surgery doi:10.1302/0301-620X.87B8. $16692 \$ 2.00$

$J$ Bone Joint Surg $[B r]$

2005;87-B:1046-9.
The capacity for biological materials to combine with inorganic salts is well established. Bio-mineralisation was an evolutionary milestone, and a key contributor to the 'cladogenesis of life' which occurred in the early Cambrian period, 570 million years ago. ${ }^{1} \mathrm{~A}$ protracted ice age in the late Precambrian era may have been the catalyst.

This phenomenom is also the bedrock upon which both the art and science of bone and joint surgery is founded. The role of calcium salts in osteogenesis has long been a focus of interest.

Clinical and experimental evidence was first published in the late 19th century. ${ }^{2}$ In the formation of bone, calcium phosphate mainly in the form of apatite, combines with collagen by both epitaxic and chemical bonding. This achieves an integrated composite material which is 'living' in that it contains both osteoblastic and osteolytic cells which are responsible for grooming the structure. Mechanical loading and strain are the fundamental influence for remodelling, the "functional adaptation" described by Wolff in $1890 .{ }^{3}$ In order to achieve a sound interface between bone and an implant, normal mechanical continuity appears essential. Any fibrous interlayer serves to alter the normal loading, producing a sclerotic surface when seen on radiographs. Such material is relatively avascular and may be susceptible to opportunist infection. In addition, it may not be able to staunch the flow of fluids and material debris which is thought to account for bone granulomata and aseptic loosening.

Calcium hydroxyapatite can be produced artificially. Maxillofacial research has indicated that it functions well as a bone filler, ${ }^{4}$ although understanding of the mechanism for this effect remains incomplete. It does not result in bone formation when placed in other tissues. Biocompatability depends on acceptance by a host cell, with no adverse immune or toxic reaction. There is evidence that the rate of degradation of the calcium salt is an important factor in osteoconduction. There may be advantages in a biphasic composition with tricalcium phosphate to achieve an optimum supply of calcium ions. ${ }^{5}$ Radiographs do not accurately reflect the histological situation in radiopaque material which can only be achieved by histological and mechanical analysis. $^{6}$

Plasma spray technology has provided the ability to coat dental and orthopaedic metals with calcium salts thus facilitating the emergence of 'bioactive' implants. ${ }^{7}$ During the 1980s, pioneering experiments with this technique were undertaken by Newesley and Osborn, ${ }^{8}$ de Groot, Geesink and Klein, ${ }^{9,10}$ Soballe et al, ${ }^{11}$ Geesink and Manley, ${ }^{12}$ and Cook, Thomas and Jarcho. ${ }^{13}$ In every comparative study with a non-coated matching device, the speed and effectiveness of bonding were dramatically improved. Coated implants had been used in dentistry since the 1970 s. ${ }^{14}$ The orthopaedic world followed rather slowly in their footsteps. The first orthopaedic application seems to have been at St Thomas' Hospital, London in $1981 .^{15}$ The Furlong (JRI Ltd, London, UK) hydroxyapatite ceramic-coated total hip replacement was introduced in 1985. Geesink followed with the Omnifit hip (Stryker Howmedica Osteonics, Allendale, New Jersey) in 1986, and the Artros group began use of their Landos system in the same year. The ABG hip (Stryker Howmedica Osteonics) arrived in 1988. Since then, most manufacturers of orthopaedic implants have developed coated prostheses for the hip, particularly as well as for the knee. Currently most implants which require anchorage to bone have been produced with coating, with success in most cases.

As is the case with innovations, the enthusiasts drew scepticism. Concerns were expressed as to possible delamination of the coating leading to aseptic loosening and of third-body wear of the bearing surfaces from hydroxyapatite grit. We are now able to review hydroxyapatite-coated implants used in a considerable range of applications up to nearly a quarter 
century after its introduction. In the main, the gloomy predictions have not been borne out. The key consideration is whether the coating contributes to success or failure. Many factors may influence the outcome of an implant, including materials, design geometry, surgical technique and patient use.

The information concerning mandibular implants is extensive. After five years $90 \%$ of dental implants are successful but this falls off to $82 \%$ by ten years. Titanium devices coated with hydroxyapatite may hold a slight advantage over uncoated versions but prejudice exists in relation to the effect of coating on the periodontal membrane. ${ }^{16}$ Implants in dental surgery are placed in a contaminated environment and a reduced $\mathrm{pH}$ through bacterial colonisation in the mouth will damage calcium phosphates.

In orthopaedics, the popularity of coated implants appears to be increasing and their applications continue to expand.

Recently the results of hip replacements coated with hydroxyapatite with a follow-up of over ten years have been presented. ${ }^{17-21}$ Fixation of the stem has proved highly successful. A wide range of design concepts have been employed. Implant shapes vary from rounded to blade type profiles, sided or not, collared or not. They may be fully or partially coated and the thickness of the coating, the method of fabrication and the purity of the calcium apatite show a considerable range. However, despite triumphal claims by the promoters of each variation, there appears to be little difference in outcome, which for four significantly differing implants has been outstanding, and as good as the best of published series of cemented hip stems..$^{22-24}$ These bioactive devices appear to have been more consistent than a variety of other uncemented stems. ${ }^{25}$

The acetabulum has also shown advantages over comparable designs of uncemented implants, although some adverse outcomes have been published. Hydroxyapatitecoating on polyethylene is clearly unsatisfactory. ${ }^{26,27} \mathrm{Back}$ side wear of the polyethylene liner in the early ABG cups has been reported as causing the formation of granulomata, significantly detracting from their reliability. The problem has been addressed with current implants employing a cup without a hole. ${ }^{28}$ There is little evidence to suggest that this complication reflects on the HA bond to bone, although possibly a substantial cement mantle would have dampened the effect. Rahbek et $\mathrm{al}^{27}$ have demonstrated that hydroxyapatite coating may improve the seal against fluid and particle migration. Early Landos cups have shown failures due to high wear ${ }^{29}$ but it is not clear whether this is a feature of metal-backed implants with thinner polyethylene, ${ }^{30}$ or is specifically related to the coating. Surgical technique may be relevant, since the problem has not been experienced universally. The trend towards hemispherical implants appears to have produced notable success ${ }^{31-33}$ and currently, reliability appears to be matching that of the stem. Improvement in the material of the bearing surface may address the problem of wear. When comparison has been made between matching implants with or without coating, the findings consistently favour the coated version. ${ }^{34}$

In view of these encouraging results why has the acceptance of this technique not become universal? Cemented devices are currently cheaper, largely as a result of commercially-based pricing strategy. Preferences for hip replacements vary from nation to nation. In Australia approximately $58 \%$ of surgeons favour uncemented prostheses, ${ }^{35}$ whereas in the United Kingdom they are the choice of approximately $13 \%{ }^{36}$ There are several criticisms of uncemented technology. An uncemented implant requires a secure interference fit, and in achieving this, the risk of perioperative fracture becomes greater. It is more common than with cemented fixation. A further concern is that should revision be required for reasons other than loosening, removal of the implant may cause excessive damage. Against this, it has been claimed that loosening in the face of sepsis is less common with the coated devices, ${ }^{37}$ and should revision be required, it may be more straightforward with the absence of cement. However, the effect of marketing efforts and national habit may be the most significant determinants.

It is unavoidable that the follow-up for cemented fixation will always be longer than with other methods. Nevertheless, in a varied collection of hip replacements with the only common feature of hydroxyapatite-coated fixation, the medium term results for aseptic loosening are outstanding and as good as the very best of cemented series. In stark contrast, experience has taught us that subtle design variation can have a dramatic effect on the reliability of cemented fixation. ${ }^{38}$ Perhaps this is the most impressive evidence for the success of hydroxyapatite coating.

The literature contains few quality randomised control trials. Bradley and Andrews ${ }^{39}$ has reported a well designed trial comparing cemented Charnley and coated Furlong prosthesis, which at ten years appears to favour the latter.

Further indication that sound biological bonding is important comes from accumulating evidence in revision surgery. Trikha et $\mathrm{al}^{40}$ report exceptional results for revision hip stems. Randomised trials are particularly difficult to design in this type of patient but reports on cemented revision do indicate an unacceptable rate of failure. ${ }^{41}$

Impaction grafting techniques have been promoted and good results reported. ${ }^{42}$ At the present time, the most popular method of revision hip surgery employs sophisticated modular systems developed by a range of manufacturers, and often using HA coatings as a method of enhancing fixation. The optimum method of fixation however remains unsolved.

Cross and Parish ${ }^{43}$ describe a large series of total knee replacements in this issue. The medium term results relating to fixation appear outstanding. This adds to a significant collection of reported outcomes in knee replacements ${ }^{44-47}$ and again indicates that the method is effective. Epinette, 
Young and Morris ${ }^{48}$ has found equally satisfactory bonding with his unix unicondylar replacement.

This technology is being applied to other joints. It has become popular in ankle arthroplasty, with excellent bonding in medium term results with the STAR ankle. ${ }^{49}$

Levy and Copeland ${ }^{50}$ report excellent reliability in shoulder resurfacing. Hydroxyapatite coating enhances the reliability of external pin fixation ${ }^{51}$ and improves the stability of pedicle screws compared with uncoated screws in the spine. $^{52-54}$

The reliability of cement, when correctly used, is excellent and remains the most common method of fixation in the United Kingdom, but poor technique is unforgiving. Similarly, excellent results have been reported with noncoated uncemented devices ${ }^{55}$ but surgical technique and design are critical. ${ }^{25}$ Many disappointing results have been reported. The design of the implant and the surgical technique have a profound influence on success in all of this area of orthopaedic practice.

The most impressive evidence in favour of hydroxyapatite coating is the rarity of reported adverse results relating to the method of fixation. In the majority of cases, it appears to offer outcomes which are consistently as good as the very best of cemented or uncemented systems, and substantially better than average. With a wide variety of design concepts and surgical techniques, it appears to provide a forgiveness for shortcomings in both design and surgical technique. Such a safety cushion offers patients better assurance of outcome. It is clear that this type of fixation has a place in modern orthopaedic practice.

\section{References}

1. Shepherd J. Climate dynamics (7) Palaeoclimatology \& Ice ages. Southampton University Tyndall Institute Lectures, 2004

2. Dreesman H. Ueber knochenplombierung. Beitr Klin Chir 1892;9:804 (in German).

3. Wolff J. Das gesetz der transformation der knochen. 1890.

4. Block MS, Kent JN. Long term radiographic evaluation of hydroxyapatite augmented mandibular alveolar ridges. J Oral Maxillofacial Surg 1984;42:793-6.

5. Nery EB, LeGeros RZ, Lynch KL, Lee K. Tissue response to biphasic calcium phosphate ceramic with different ratios of HA/beta TCP in periodontal osseous defects. J Periodontol 1992;63:729-35.

6. Boivin G, Meunier PJ. The mineralization of bone tissue: a forgotten dimension in osteoporosis research. Osteoporos Int 2003;14(Suppl 3):19-24.

7. Jarcho M, Kay JF, Gumaer KI, Doremus RH, Drobeck HP. Tissue, cellular and subcellular events at a bone-ceramic hydroxylapatite interface. J Bioeng 1977;1: 79-92.

8. Newesly H, Osborn JF. Structure and texture of calcium phosphate in ceramics: 3rd conference on materials, for use in medicine and biology. Keele University, Manchester, 1978.

9. de Groot K, Geesink R, Klein CP. Plasma sprayed coatings of hydroxylapatite. J Biomed Materials Res 1987;21:375-81.

10. Geesink R, de Groot K, Klein CPAT. Bonding of bone to apatite-coated implants. J Bone Joint Surg [Br] 1988;70-B:17-22.

11. Soballe $K$, Hansen ES, Brockstedt-Rasmussen $\mathbf{H}$, et al. Fixation of titanium hydroxyapatite coated implants in osteopenic bone. J Arthroplasty 1991;6:307-16.

12. Geesink RGT, Manley MT, ed. Hydroxyapatite coatings in orthopaedic surgery. New York: Raven Press, 1993.

13. Cook SD, Thomas KA, Jarcho M. Hydroxyapatite-coated titanium for orthopaedic implant applications. Clin Orthop 1988;232:225-43.

14. Jarcho M. Retrospective analysis of hydroxyapatite development for oral implant applications. Dent Clin North Am 1992;36:19-26
15. Butler Manuel PA, James SE, Shepperd JA. Pelvic underpinning: 8 years experience. J Bone Joint Surg [Br] 1992;74-B:74-7.

16. Jokstad A, Braegger U, Carr A, et al. Quality of dental implants. Int Dent J 2003; 53:409-43.

17. George $\mathbf{M}$, Mueller M, Shepperd JA. Two decades of hydroxyapatite coatings in total hip replacement. In: Epinette J-A, Manley MT, eds. Fifteen years of clinical experience with hydroxyapatite coatings in joint arthroplasty. France: Springer-Verlag, 2004:211-16.

18. Vidalain J-P. Corail stem long term results based on the 15-year artro group experience. In: Epinette J-A, Manley MT, eds. Fifteen years of clinical experience with hydroxyapatite coatings in joint arthroplasty. France: Springer-Verlag, 2004:217-24.

19. Reikeras 0 , Gunderson RB. Excellent results of HA coating on a grit-blasted stem: 245 patients followed 8-12 years. Acta Orthop Scand 2003;74:140-5.

20. Robertson A, Lavalette D, Morgan S, Angus PD. The hydroxyapatite-coated JRI Furlong hip: outcome in patients under the age of 55 years. J Bone Joint Surg $[\mathrm{Br}]$ 2005;87-B:12-15

21. D'Antonio JA, Capello WN, Manley MT, Geesink RJ. Hydroxyapatite femoral stems for total hip arthroplasty: 10-13 year follow-up. Clin Orthop 2001;393:101-11.

22. Williams HD, Browne G, Gie GA, et al. The Exeter universal cemented femoral component at 8 to 12 years: a study of the first 325 hips. J Bone Joint Surg [Br]2002; 84-B:324-34

23. Gerrisma-Bleeker CL, Deutman R, Mulder TJ, Steinberg JDJ. The Stanmore total hip replacement: a 22-year follow-up. J Bone Joint Surg [Br] 2000;82-B:97-102.

24. Callaghan JJ, Templeton JE, Liu SS, et al. Results of Charnley total hip arthroplasty at a minimum of thirty years: a concise follow-up of a previous report. J Bone Joint Surg [Am] 2004;86-A:690-5.

25. Swedish National Hip Arthroplasty Register, 2004.

26. Morscher E, Hefti A, Aebi U. Severe osteolysis after third body wear due to hydroxyapatite particles from acetabular cup coating. J Bone Joint Surg [Br] 1998; 80-B:267-72.

27. Rahbek $\mathbf{0}$, Lind $\mathbf{M}, \mathbf{O v e r g a a r d ~ S , ~ e t ~ a l . ~ S e a l i n g ~ e f f e c t ~ o f ~ h y d r o x y a p a t i t e ~ c o a t i n g ~ o n ~}$ peri-implant migration of particles: an experimental study in dogs. J Bone Joint Surg [Br] 2001;83-B:441-7.

28. Duffy P, Sher JL, Partington PF. Premature wear and osteolysis in an HA-coated, uncemented total hip arthroplasty. J Bone Joint Surg [Br] 2004;86-B:34-8.

29. Lai KA, Shen WJ, Chen $\mathbf{C H}$, et al. Failure of hydroxyapatite-coated acetabular cups: ten-year follow-up of 86 Landos Atol arthroplasties. J Bone Joint Surg [Br]2002; 84-B:641-6.

30. Ritter MA, Keating EM, Faris PM, Brugo G. Metal backed acetabular cups in total hip arthroplasty. J Bone Joint Surg [Br] 1990;72-A:672-7.

31. Bonutti PM, Effingham IL. Five year results of a second generation hydroxyapatite coated SAcetabular implant [abstract]. American Academy of Orthopaedic Surgeons Meeting, 2004

32. Epinette JA, Manley MT, D'Antonio JA, Edidin AA, Capello WN. A 10 year minimum follow up of hydroxyapatite-coated threaded cups: clinical, radiologic and survivorship analyses with comparison to the literature. J Arthroplasty 2003;18:140-8.

33. Dambreville A. Minimum 10 year follow up of the hydroxyapatite coated atlas cup. In: Epinette J-A, Manley MT, eds. Fifteen years of clinical experience with hydroxyapatite coatings in joint arthroplasty. France: Springer-Verlag, 2004:325-8.

34. Havelin LI, Vollset SE, Engesaeter LB. Revision for aseptic loosening of uncemented cups in 4,352 primary total hip prostheses: a report from the Norwegian Arthroplasty Register. Acta Orthop Scand 1995;66:494-500.

35. Graves SE, Davidson D, Ingerson L, et al. Australian Orthopaedic Association National Joint Replacement Registry. Med J Aust 2004;180(5 Suppl):31-4.

36. British National Joint Register, 2004.

37. Moroni A, Vannini F, Mosca M, Giannini S. State of the art review: techniques to avoid pin loosening and infection in external fixation. J Orthop Trauma 2002;16:189-95.

38. Roy N, Hossain S, Ayeko C, et al. Capital hip arthroplasty: 3-8 year follow up of 208 primary hip replacements. Acta Orthop Scand 2002;73:400-2

39. Bradley JG, Andrews CM. Furlong calcium hydroxyapatite coated cementless prosthesis versus Charnley cemented prosthesis [abstract]. J Bone Joint Surg [Br] 1999;81-B (Suppl I):9

40. Trikha PS, Singh S, Edge J, Lewis J, Mitchell P. Hydroxyapatite ceramic coated femoral stems in revision hip surgery [abstract]. Procs American Academy of Orthopaedic Surgeons Meeting, 2005.

41. Lie SA, Havelin LI, Furnes ON, Engesaeter LB, Vollset SE. Failure rates for 4762 revision total hip arthroplasties in the Norwegian Arthroplasty Register. J Bone Joint Surg [Br] 2004;86-B:504-9

42. Halliday BR, English HW, Timperley AJ, Gie GA, Ling RS. Femoral impaction grafting with cement in revision total hip replacement: evolution of the technique and results. J Bone Joint Surg [Br] 2003;85-B:809-17

43. Cross MJ, Parish EN. A hydroxyapatite-coated total knee replacement: prospective analysis of 1000 patients. J Bone Joint Surg [Br]2005;87-B:1073-6. 
44. Nesse E, Waage Nielsen E, Bastian D. Cemented versus cementless revision femoral stems using morcelised allograft: a prospective, randomised study with 5 years follow-up. Z Orthop Ihre Grenzgebo 2003;141:678-83 (in German).

45. Murty AN, Scott G, Freeman MA. Hydroxyapatite-coated femoral components in total knee arthroplasty: medium term results. J Arthroplasty 2003;18:844-51.

46. Oliver MC, Keast-Butler OD, Hinves BL, Shepperd JA. A hydroxyapatite-coated Insall-Burstein 2 total knee replacement. J Bone Joint Surg [Br] 2005;87-B:478-82.

47. Cameron HU. HA versus grit blasted tibial components in total knee replacement. Acta Orthop Belg 1997;63(Suppl 1):47-9.

48. Epinette J-A, Young D, Morris H. Hydroxyapatite-coated unicompartmental knee arthroplasty: a 12-year experience with the HA Unix prosthesis. In: Epinette J-A Manley MT, eds. Fifteen years of clinical experience with hydroxyapatite coatings in joint arthroplasty. France: Springer-Verlag, 2004:417-30.

49. Anderson T, Montgomery F, Carlsson A. Uncemented STAR total ankle prostheses. J Bone Joint Surg [Am] 2004;86-A(Suppl 1):103-11.
50. Levy 0, Copeland SA. Cementless surface replacement arthroplasty (Copeland (SRA)) for osteoarthritis of the shoulder. J Shoulder Elbow Surg 2004;13:266-71.

51. Magyar G, Toksvig-Larsen S, Moroni A. Hydroxyapatite coating of threaded pins enhances fixation. J Bone Joint Surg [Br] 1997;79-B:487-9.

52. Sanden B, Olerud C, Johansson C, Larsson S. Improved bone screw interface with hydroxyapatite coating: an in vivo study of loaded pedicle screws in sheep. Spine 2001;26:2673-8.

53. Fini M, Giavaresi G, Greggi T, et al. Biological assessment of the bone-screw interface after insertion of uncoated and hydroxyapatite-coated pedicular screws in osteopenic sheep. J Biomed Mater Res A 2003;66:176-83.

54. Sanden B, Olerud C, Petren-Mallmin M, Larsson S. Hydroxyapatite coating improves fixation of pedicle screws: a clinical study. J Bone Joint Surg [Br]2002;84-B:387-91.

55. Garcia-Cimbrelo E, Cruz-Pardos A, Madero R, Ortega-Andreu M. Total hip arthroplasty with use of the cementless Zweymuller Alloclassic system: a ten to thirteen-year follow up study. J Bone Joint Study [Am] 2003;85-A:296-303. 